\title{
LA METODOLOGÍA EXPRESIONISTA EN LA EDUCACIÓN ARTÍSTICA Y SU CONTRIBUCIÓN AL ARTETERAPIA.
}

\section{The Expressionist Methodology in the Artistic Teaching and its contribution to Art Therapy.}

\author{
Ma Dolores LóPez Martínez \\ Departamento de Expresión Plástica, Musical y Dinámica. Facultad de Educación. \\ Universidad de Murcia. \\ fendi@um.es
}

Recibido: 13 de Junio de 2010

Aprobado: 18 de septiembre de 2010

\begin{abstract}
Resumen:
Entre 1920 a 1940 aparece la Corriente Expresionista, una nueva metodología de Enseñanza Artística concebida desde la expresión libre y emocional de la persona, sin la intervención de modelos, ni instrucciones previas, sólo aquellas adquiridas de forma autónoma por la experimentación con las técnicas y materiales artísticos. Esta didáctica artística conseguirá aunar la pedagogía progresista con los nuevos discursos conceptuales y técnicos promulgados por los artistas vanguardistas. A su vez, volverá a cuestionar los objetivos y metodologías de la enseñanza artística cuya inf uencia creará un entorno propicio en el ámbito educativo para la aparición y la expansión profesional del Arteterapia.
\end{abstract}

Palabras clave: Arteterapia, Terapia Artística, Corriente Expresionista, Educación Artística.

Martínez, D. 201 1: La metodología expresionista en la educación artística y su contribución al arteterapia. Arte, Individuo y Sociedad, 23 (1), 81-88.

\begin{abstract}
Abstrac:
In 1920 the Expressionist Pedagogy continued until 1940. It consisted of a new methodology ofArtistic Teaching based on a person's free and emotional expression. It did not take into consideration previous instructional or teaching techniques; only those acquired in an autonomous way by experimenting with artistic techniques and materials were considered. This artistic didactic was able to combine the progressive pedagogy and the new technical and conceptual speeches which were promulgated by the avant-gard artists. Moreover, it will question the objectives and methodologies of the artistic teaching whose inf uence will create a favorable environment in the educativef eld due to the appearance and the professional expansion of Art Therapy.
\end{abstract}

Key words: Art therapy, Artistic Therapy, Expressionist Pedagogy, Artistic Education.

Sumario: 1. Introducción. 2. La incursión de los Artistas de Vanguardia en el ámbito de la Educación Artística. 3. Los Métodos Expresivos en la Educación Artística como componentes claves en el sur gimiento del Arteterapia. 4. Conclusión. 5. Bibliografía. 


\section{Introducción}

La creencia utópica perseguida por los artistas de vanguardia sobre la emancipación de la humanidad a través de un arte autónomo, libre de imposiciones externas, se ve cristalizada en los objetivos didácticos de la Corriente Expresionista, ya emprendida por los movimientos progresistas de índole rousseauniana.

La flosofía central de esta tendencia acentúa la consideración de la educación artística como un instrumento óptimo para el cultivo emocional del alumnado y el desarrollo de sus facultades creadoras innatas, mediante la realización de actividades plásticas de carácter libre, en las que el alumno elige de forma autónoma el material, el tema, la técnica, etc., sin unas pautas impuestas por el profesor que, tradicionalmente, suele perseguir unos conocimientos artísticos concretos. “(...) buscaba trascender el conocimiento del arte en beneficio del crecimiento personal, moral o social. Un canto a la libertad humana que vio en la educación artística la manera de reificarse, de reconstruir al ser humano desintegrado y hacer posible la utopía". (Aguirre, 2005, pág. 219).

Desde esta perspectiva, se revaloriza la forma natural que tienen los niños de utilizar los medios plásticos para comunicar sus propios pensamientos, sentimientos o emociones. La autoexpresión, por lo tanto, no puede ser enseñada, ya que cualquier imposición normativa, además de frustrar la verdadera expresión del "yo", puede causar en la persona inhibiciones o bloqueos. El hecho de proporcionar a los alumnos los recursos necesarios, para potenciar sus necesidades expresivas, puede promover su autoconf anza, su autoestima y una mayor identif cación con lo que hace. "Sólo la educación en su sentido más amplio, como crecimiento guiado, expansión fomentada, crianza tierna, puede asegurar que la vida sea vivida en toda su natural espontaneidad creadora, en toda su plenitud sensorial, emocional e intelectual”. (Read, 1982, pág. 207).

Se enfatizan los benef cios que proporcionan la vivencia del proceso creativo y la experimentación con los materiales plásticos sin la presión de que el acabado fnal deba cumplir unos parámetros estéticos determinados. "La perfección técnica tiene muy poca vinculación con la autoexpresión, y la producción de obras artísticas técnicamente excelentes, puede estar muy lejos de las necesidades expresivas reales del autor". (Lowenfeld, 1980, pág.28).

El maestro debe favorecer el autodescubrimiento y la exteriorización de las emociones con una gran variedad de métodos y materiales que potencien el juego y la imaginación, sin que sus intervenciones sean coercitivas. Por lo tanto, la evaluación de los logros técnicos del alumno no adquiere importancia. La motivación del alumnado en un ambiente de con fanza puede evitar cualquier interferencia que consiga desvirtuar su manifestación personal. De esta manera, el niño ejercita la seguridad en sí mismo, cuando se le ofrece la oportunidad de imponer sus propias soluciones ante situaciones nuevas que pueden surgir, por ejemplo, con el comportamiento inesperado ante los materiales. La observación de las intuiciones del niño y cómo estas van guiando los propios estímulos creativos, transformando sus reacciones en cada gesto, convierte a las actividades plásticas en experiencias de gran valor tanto pedagógico como psicológico. 


\section{La incursión de los artistas de vanguardia en el ámbito de la educación artística}

El interés por llevar a cabo los conceptos de la enseñanza artística expresionista al aula procedió, en su mayoría, de artistas vanguardistas profundamente comprometidos con la idea sobre la existencia de una a f nidad entre la actividad del artista y la expresión gráf ca del niño. (Ef and, 2002).

En Viena, Franz Cizek fue uno de los primeros artistas y profesores de dibujo que concibió las obras grá $\mathrm{f}$ cas de los niños como obras de arte. Cizek estaba vinculado al movimiento artístico de la Seccesion, grupo afín a Die Brücke o Blaue Reiter alemanes, los cuales en 1908 organizan una exposición que incluye obras infantiles, muestra de la admiración que les suscitaban.

Años más tarde, entre las décadas de 1920 a 1940, aparecen profesores-artistas: Victor D'Amico, Natalie Cole, Marion Richardson, Maria Petrie, Henry Schaef ferSimmern y Florence Cane, los cuales coincidían con Cizek en la idea de considerar al niño un artista con grandes deseos de poder exteriorizar sus inquietudes, obstaculizadas, en muchas ocasiones, por los métodos tradicionales de la enseñanza. Postulaban que un buen maestro de educación artística debía ser artista:

Creo que es absolutamente imposible que alguien que no sea un artista consiga enseñar arte. El profesor de arte hecho por encar go depende de métodos estandarizados más que de su propia sensibilidad. Nadie que no sea un artista posee la delicada intuición necesaria para reconocer aquello que otra persona está tratando de expresar. (Mangravite, 1932, pág. 33).

Los artistas del momento asociaban su lucha por conseguir un arte incontaminado como símbolo para promover soluciones a los conf ictos metafísicos de una sociedad corrompida, asumiendo un rol libertador. La f gura del niño concebido como artista y la incursión de algunos artistas contemporáneos en el ámbito de la educación supone un factor importante para llevar a cabo esta empresa, a través del trabajo artístico conjunto capaz de preservar la armonía y autenticidad innatas del ser. El niño artista recibió así el papel de salvador de la sociedad. El equivalente educativo de esta flosofía fue la difusión de una educación expresiva centrada en el niño. "Se está descubriendo al artista que hay en el niño que todos llevamos dentro y que está quitando la mordaza de la represión al niño que hay dentro del hombre común para que éste pueda realizarse de forma completa”. (Rugg y Shumaker, 1928, págs. 62-63).

Muchos profesores con formación artística empiezan a introducir en la escuela los métodos y técnicas utilizados por los artistas de las vanguardias. Las nuevas metodologías del arte contemporáneo, al mismo tiempo que ofrecían una gran variedad de recursos creativos, se adaptaban fácilmente a la habilidad y economía de cualquier escolar, además de favorecer el desarrollo personal en general.

D'Amico consiguió con su obra, Creative Teaching Art (1942), la introducción de algunas de estas técnicas, entre otras: el collage, la experimentación con materiales no artísticos o de desecho, etc., con la intención de potenciar la libre expresión.

Cole tomaba en sus clases como punto de partida las experiencias reales de sus alumnos. Los niños hablaban en grupo sobre sus vivencias cotidianas para después pintarlas o dibujarlas: "Es necesario estimular la mente y las emociones del niño 
hacia alguna cosa y que tenga ganas de pintar antes de que pueda hacerlo bien”. (Cole, 1940, págs. 3-4).

La conexión establecida entre arte y vida se hacía evidente en su pedagogía.

Richardson trabajaba con imágenes mentales antes de empezar un dibujo. Los niños cerraban los ojos y debían obtener alguna imagen concreta con el f $\mathrm{n}$ de representarla plásticamente. En su obra Art and the child (1946), expone su método en el que se encuentran analogías con el modelo interior surrealista propagado por Breton.

(...) sabía que los niños obtenían sus mejores resultados cuando pintaban a partir de una imagen mental; esta técnica resultaba rica y fructífera para la mayoría, pero algunos de ellos eran incapaces de escoger en su cambiante y caleidoscópico catálogo interior. (Richardson, 1946, pág.14).

Petrie indica en Art and Regeneration (1946) que las actividades artísticas podían ayudar a aquellas personas que sufrían alguna enfermedad física, mental e incluso ser un posible remedio para una sociedad enferma por las secuelas de la Segunda Guerra Mundial.

Schaeffer-Simmern muestra una línea similar a la de Petrie en sus experimentos de enseñanza artística con grupos de niños y adolescentes con retraso mental y con problemas de delincuencia. Su obra The unfolding of artistic activity (1948) describe las vivencias con estos colectivos y la función mediadora de las actividades artísticas.

\section{Los métodos expresivos en la educación artística como componentes claves en el surgimiento del arteterapia}

Sin embargo, años atrás Cane ya había conseguido reencontrar arte y terapia de nuevo, esta vez bajo un entorno distinto: la Escuela de Walden, de Nueva York, fundada y dirigida por su hermana Naumburg.

Naumburg introduce en su escuela conceptos educativos in $\mathrm{f}$ uenciados por la corriente psicoanalítica del momento y la importancia de los factores inconscientes tanto en la educación como en la psicoterapia. En su currículo otor gó gran valor a las actividades artísticas. En ellas veía un método de automotivación para aprender de forma efectiva a canalizar emociones perjudiciales para la personalidad del niño.

Cane también profesaba en sus enseñanzas el psicoanálisis freudiano y de Jung. Desde su punto de vista, el verdadero f n del maestro consistía en no reprimir las emociones del niño y ayudarle a liberarse de sus defensas estereotipadas re fejadas en los dibujos. A pesar del carácter progresista de Walden School, Cane encuentra allí una educación artística enfocada hacia el realismo y el desarrollo de habilidades técnicas.

En 1920, comienza a dar clases con Naumburg y a poner en práctica sus métodos de trabajo, basados en el automatismo con el uso libre del movimiento, del sonido y la técnica gráf ca del Garabateo. El objetivo principal consistía en bajar las defensas de los niños y dar rienda suelta a las fantasías del inconsciente. A la hora de realizar las obras plásticas, insistía en la idea de no sugerir temas concretos, que fuesen los alumnos quienes lo eligieran según sus intereses. 
La calidad de la pintura aumenta inevitablemente si el niño se desarrolla como individuo, del mismo modo que su desarrollo como pintor contribuye a su crecimiento. En consecuencia, mis enseñanzas se han dirigido siempre a la liberación y el crecimiento del alma del niño a través del juego, el trabajo y la autodisciplina que exige la pintura. (Cane, 1983, pág.44)

Naumburg comienza a experimentar con las técnicas de Cane en sus clases de arte. Sus conocimientos como psicóloga y educadora le llevan a observar en los dibujos espontáneos de sus alumnos un discurso simbólico de gran valor comunicativo.A partir de entonces, comienza a integrar las técnicas de libre expresión de Cane y las teorías psicoanalíticas aprendidas en sus propias sesiones de psicoanálisis personal. En 1928 publica su primer libro, The Child and the World, basado en sus experiencias con los niños de Walden School. Pronto se dio cuenta del poder terapéutico de la fusión de ambos métodos, lo que le llevará a experimentarlos y compartirlos con psiquiatras como el Dr.Lewis.

Cane publica, un año más tarde, la versión de su flosofía en un momento muy posterior de su carrera en The Artist in Each of Us (1951). Para autores como Junge y Asawa (1994), el pensamiento de ambas hermanas def nió durante la década de 1960 y 1970 los enfoques posteriores del arteterapia; la orientación de Naumburg más enfocada hacia la psicoterapia y la de Cane, hacia los benef cios saludables del proceso creativo.

La Corriente Expresionista dejó en manos de muchos profesores de educación artística los componentes claves en el sur gimiento del arteterapia como disciplina. Sus métodos de trabajo en pro del crecimiento emocional y creativo del alumno a través del uso libre de los medios plásticos, supieron vincular las técnicas de los ar tistas modernos, las concepciones educativas de la escuela progresista y las corrientes psicológicas del momento, sobre todo las teorías de Piaget y Freud, relacionadas con la evolución psicológica del niño. Todas estas circunstancias dieron lugar a un ambiente que favoreció el nacimiento del arteterapia especialmente en E.E.U.U. e Inglaterra entre la década de 1930 y 1940.

En primer lugar, la enseñanza progresista logró difundirse por toda Europa, aunque entremezclada con otras corrientes pedagógicas. Su carácter heterogéneo deter minó que la orientación expresionista no tuviera tanto arraigo. La Segunda Guerra Mundial también supuso un freno importante en el ambiente educativo europeo. La emigración a otros países dispersó la ideología expresionista. Sin embargo, años más tarde volvería a arraigar, especialmente en Inglaterra. Los intentos de Read, por crear un movimiento pacif sta a través del arte, lograron resur gir el enfoque no directivo entre los profesores de plástica, renovando con intensidad el ambiente de la educación artística inglesa. Su obra Educación por el arte, (1943), fue una referencia clave para los primeros arteterapeutas ingleses.

En E.E.U.U., la corriente expresionista empieza a extenderse con fuerza a partir de la década de 1930. Los movimientos de reforma sociales como el sufragismo femenino y el movimiento para los centros de asistencia, en su empeño por mejorar la vida del individuo, sintonizaron con las teorías de Dewey y sus seguidores. La idea de impartir una educación, centrada en el arte como experiencia, consigue reemplazar la búsqueda de la belleza por acciones enfocadas hacia actividades artísticas que 
solucionasen los problemas vitales comunitarios de índole social. ${ }^{1}$ Otro aspecto interesante fue el gran éxodo de inmigrantes provocado por la Segunda Guerra Mundial. Muchos artistas expresionistas y surrealistas, maestros de la Bauhaus alemana e historiadores del arte consiguieron enriquecer el escenario intelectual americano, creando un escenario ideal para el nacimiento y desarrollo del arteterapia.

Por último, las investigaciones sobre la creatividad y la obra deVictor Lowenfeld, El desarrollo de la capacidad creadora (1947), muy difundida en ambos contextos geográf cos, también fueron grandes referentes para muchos arteterapeutas.

Todos estos acontecimientos facilitaron el camino para que ambos países consiguieran ser pioneros en el uso del arte como herramienta terapéutica.

\section{Conclusiones}

El marco sociocultural de las sociedades norteamericana e inglesa en las décadas de 1930-1940 favoreció que los hallazgos descubiertos por los educadores de arte se compartieran, posteriormente, con las investigaciones de muchos psiquiatras y psicólogos, interesados en las manifestaciones artísticas de sus pacientes. La conexión interdisciplinar entre los profesionales de la Educación Artística, muy infuenciados en ese momento por el arte de vanguardia Arte, y el ámbito Médico/Psiquiátrico, iniciada con la alianza de autoras como Naumbur g y Cane, consiguió construir los cimientos del corpus del Arteterapia y sus raíces epistemológicas.

1. Desde el Ámbito Médico/Psiquiátrico, porque comienza a mostrarse un interés por el valor expresivo y comunicativo de las producciones plásticas de los enfermos mentales y el efecto terapéutico del proceso creativo.

2. Y desde el Ámbito Artístico-Educactivo, porque los artistas de vanguardia empiezan a concebir sus obras y el proceso creativo como un medio de proyección subjetiva. Además, sus innovaciones discursivas y metodológicas, centradas en la experimentación, expresión y comunicación, darán paso al énfasis en el fomento de la desinhibición y la creatividad. Características que muchos profesores de arte tomarán como referente en la introducción de la educación emocional donde la autoexpresión y desarrollo creativo del individuo pasarán a un primer plano.

La Corriente Expresionista aúna las contribuciones de ambos contextos. Este hecho ha ayudado a con f gurar la metodología que se aplica actualmente en los tratamientos de Arteterapia y al desarrollo de esta joven disciplina.

A raíz de sus fundamentos discursivos la utilización de los medios plástico-visuales comienza a concebirse como herramientas que propician:

- La proyección subjetiva del individuo.

- El desarrollo personal a través de la autoexploración, expresión y comunicación con los medios plástico-visuales.

- La desinhibición y la creatividad. 
Todos estos elementos, han hecho posible que los procesos creativos y las obras generadas en las diversas actividades plásticas sean factores primordiales para la resolución de conf ictos y el camino hacia el cambio.

\section{Bibliografía}

Aguirre, I. 2005: Teorías y prácticas en educación artística. Ideas para la revisión pragmatista de la experiencia estética. Pamplona: Universidad Pública de Navarra.

Cole, N. 1940: The arts in the classroom. Nueva York: John Day.

Cane, F. 1983: The artist in each of us. New York: Pantheon.

Ef and, A.D. 2002: Una historia de la educación del arte: Tendencias intelectuales y sociales en la enseñanza de las artes visuales. Barcelona: Paidós.

Junge, M.B. y Asawa, P.P. 1994: A history of Art therapy in the United States. Mundelein, IL: American Art therapy Association.

Lowenfeld, V. y Lambert Brittain,W . 1980: Desarrollo de la Capacidad Creadora. Buenos Aires: Kapelusz.

Mangravite, P. 1932: The artist and child. En: G. Hartman y A. Shumaker (Comps.): Creative expression (pp.29-33). Nueva York: John Day.

Naumburg, M. 1947: Studies of the free art expresión of behavior problem children and adolescents as a means of diagnosis and therapy. Nueva York: Collage Press.

Naumburg, M. 1987: Dinamically oriented art therapy: its principles and practices: Illustrated with three case studies. Chicago: Magnolia Street Publishers.

Read, H. 1982: Educación por el arte. Barcelona: Paidós Educador.

Richardson, M. 1946: Art and the child. Peoria, IL: Charles A. Bennet Co.

Rugg, H. y Shumaker, A. 1928: The child-centered school. Nueva York: World book.

\section{Notas}

1. Un ejemplo de esta empresa fue el proyecto de educación artística de Otawa aplicado entre 1933 y 1938 donde se empiezan a explorar las posibilidades de introducir el arte en la vida cotidiana de la comunidad. 